JOTS, 2/1, 2018: 7-23

\title{
Uygurca Bir Sivil Hayat Belgesi: Maitrisimit
}

\section{A Civilian Life Documentary in Uighur: Maitrisimit}

\author{
Fatih BAKIRCI \\ Mimar Sinan Fine Arts University (İstanbul/Turkey) \\ E-mail: fthbkrc@hotmail.com
}

The Uighur that politically dominant on the stage of history since the 8th century, spread across different geographical regions based on such political structuring encountered different languages and cultures due to political, cultural and religious reason and interacted with these. There is court of Buddhist in those different interacted fields, too. The work called Maitrisimit translated from Tocharian is one of texts of Buddhist court that took an important place in Old Uighur Turkish works. GABAIN and TEKIN previously laid emphasis on the fact that Maitrisimit which has a dynamic and dramatic narration was a theatrical production and staged. Based on these remarks, this assertion in which the theatrical terms and concepts in the work were first identified focuses on the question why such a religious work includes theatrical aptitude style wise by giving examples from the Berlin (B) collection and the copy of Hami (H). It is seen that this work in an attempt to convey the Buddhist doctrines to the public in a more understandable way can be considered more of a civilian life documentary in terms of language and style, as compared to Sütra and Abhidarma's, the other religious texts of the period, which belong to Buddhist community.

Key Words: Maitrisimit, Old Uighur, Buddhism, theatre, style. 


\section{J(৫)}

\section{Giriş}

Çin kaynaklarında Asya Hunlarından geldikleri belirtilen Uygurlar V. yüzyılın ikinci yarısında bir beylik kurmuşlar, daha sonra bütün yukarı Orta Asya'ya yayıldığı anlaşılan Töleslerin bir kısmını teşkil ederek Göktürklere bağlanmışlardır (Kafesoğlu 1976: 725). Göktürklerin hâkimiyeti altında uzun bir süre yaşayan Basmıl, Karluk ve Uygur boyları 742-743 yıllarında Göktürk kağanı Ozmış’ı mağlup edip Göktürk Devletini ortadan kaldırmışlardır. Basmıl boylarının başkanlığında yeni bir kağanlık kurulmuş, Uygurlar bu kağanlığın Doğu Yabguluğunu teşkil etmişlerdir. 744 yılında Uygur yabgusu, Basmıl kağanını mağlup ederek kendisini Uygur kağanı olarak ilan etmiş böylece ilk Uygur Kağanlığı kurulmuştur (Taşağıl 2002: 216-217).

744 yılında merkezi Orhon kıyılarında olmak üzere Uygur Devletini kuran On Uygurlar, 840 yılına kadar bu bölgede yaşamışlardır. 840'ta 100.000 kişilik Kırgiz, Uygur başkentine saldırmış ve halkı kılıçtan geçirmiştir. Ölümden kurtulanlar dört bir yana dağllıp çeşitli yerlere göç etmişlerdir (Çandarlıoğlu 2002: 11-31). Asya'nın daha güney bölgelerine göç eden Uygurlardan bir grup Çin'in batısındaki Sha-chou şehrine yerleşip Maniheizm'i benimsemiştir. Siyasî hâkimiyetleri çok kısa süren Sha-chou Uygurları önce Kitanların daha sonra da Tangutların hâkimiyeti altına girmişler, bir diğer grup ise bugünkü Kansu bölgesi yakınlarına gidip Kan-chou Uygur Devletini kurmuşlardır. Kendilerine ‘Sarı Uygurlar' da denilen Kansu Uygurları X. yüzyıldan itibaren Uygurların kuvvet merkezi hâline gelmiştir. Bu Uygurlar da Sha-chou Uygurları gibi XI. yüzyıldan sonra Tangut ve Kitanların hâkimiyetlerini tanımışlardır (Çandarlıoğlu 2002: 31-32).

Güneybatıya giden 15 Uygur boyundan bir kısmı Tibetlilere bağlanmış, asıl büyük grup ise Beşbalık, Karaşar, Koço (Hoço) ve Turfan şehirlerine yerleşerek Kao-chang (Turfan) Uygur Devletini kurmuşlardır. Bu devlet önce 1206 yılında Kara Hıtay devletine, sonra da 1209'da Çingis Han'a bağlanmıştır. Daha sonra Çağatay Han'ı Tuğluk Temür (1346-1363)'den Vais Han'a (1471-1432) kadar Doğu Çağatay Ulusunun hâkimiyetinde kalmıştır. Çağataylıların zayıfladığı dönemde Çinlilerin Ye-mi-li Huo-che (Emil Hoca) ve Su-t'an A-li (Sultan Ali) isminde iki kişi tarafından Uygurlar idare edilmişstir (İzgi 1987: 40-46). 


\section{J(৫)}

Bu farklı bölgelerde çeşitli inanç sistemleriyle karşılaşan ve bunları benimseyen Uygurlar, özellikle Kansu (Kan-chou [Sarı]) ve Koço (Kao-chang [Turfan]) Uygurları döneminde bu inanç sistemleriyle ilgili büyük bir çeviri etkinliği gerçekleştirmişlerdir. Bu çeviriler daha çok bağlandıkları Maniheizm ve Budizm gibi inanç sistemleriyle ilgili dinî metinlerdir. Soğdca, Çince, Toharca, Sanskritçe ve Tibetçeden Uygur Türkçesine çevrilen bu eserler (eserler için bk. Özönder 2002: 481-501), sadece dâhil oldukları yeni inanç sistemlerinin öğrenilmesi için değil, aynı zamanda inanç sistemlerine bağlı olarak kutsal metin yazmanın ve okumanın kişiye kazandıracağı sevap anlayışı da düşünülerek tercüme edilmişlerdir. Nitekim SHIMiN'in (2002: 788) konuyla ilgili açılamaları da buna işaret etmektedir: "Uygur soyluları ve hatta sıradan insanlar, hayırseverlik ve dindarlığın gereklerini, yani 'sevap işlemek' (buyan < Skr. puṇya) için adına Budist tapınaklar, heykeller, freskler yapmak ve sūtra kopyaları (Budist kutsal yazmalar) çoğaltmak için hatırı sayılır ölçüde emek vermişlerdir."

Uygurların sosyo-kültürel yapılarında ve ortaya koymuş oldukları sanat olaylarında temsil ettikleri dinlerin çok büyük bir rolü vardır. Çünkü sanat eserlerinin ve plastik sanatlarının büyük bir çoğunluğu dinî konulara bağlı olarak ele alınmıştır. Çeşitli dinler bu topluluk içerisinde yaşama şansı bulmuş, kimisi uzun süreli büyük bir kitleyi etkileyebilmiş, kimi resmî devlet dini olarak kabul görmüş, kimisi de kısa sürede etkisini kaybetmiş̧ir. Bunlar arasında Hristiyanlık, Zerdüştlük ve Budizm'deki bazı unsurların birleşmesinden ortaya çıkan Maniheizm yer almaktadır. Bu inanç sistemi Uygur soyluları tarafından 762 yılında Moğolistan'da Uygur Hanlı̆̆ döneminde kabul edilmiştir (Tekin 1962: 1-11).

Manihaizm, Uygurların Turfan'a göçünden sonra da bir süre varlığını devam ettirdi. Uygurlar yerli halkın etkisiyle yavaş yavaş Budizm'e inanmaya ve Budist kutsal metinlerini Uygurcaya çevirmeye başladılar. Günümüz arkeologları tarafından bu bölgede bulunan pek çok Uygur elyazmasında ve Budist duvar resminde de gösterildiği gibi tapınakların etrafındaki toplanma yerlerinde yap1lan Budist festivallerde, vaazlardan, Budist içerikli dramalar ve hikâyeler anlatmaya kadar pek çok faaliyete yer verilirdi (Shimin 2002: 788).

$\mathrm{Bu}$ drama faaliyetlerinin yanı sıra Uygurlardaki tiyatro sanatının varlığını gösteren önemli bir husus da 982 yılında Son Hanedanlığı (960-1279) elçisi olarak 


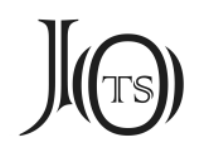

Koçu'yu ziyaret eden WANG YANDE'nin bazı büyükelçilik kayıtlarındaki yazılarında şehirle ilgili yaptığı canlı tasvirlerdir: “(...) Daha sonra Uygurların Kralı bizi akşama kadar müzikle, ziyafetle ve dramatik oyunlarla ağırladı." (Song Shi: Bölüm1/490, Shimin 2002'den).

\section{Burkancl Çevreye Ait Maytrisimit Nom Bitig}

Uygurca Burkancı drama metinlerinin varlığının işaret ettiği gibi Koçu'da X. yüzylla kadar bir tür dramatik temsil gösterimleri yapılmıştır (Shimin 2002: 788). Bu drama metinlerinden biri de Maytrisimit Nom Bitig'dir. Bu metin (Toharca A dilinde [Karaşehr-Koço dilinde]) düz yazı ve şiir formunda yazılmış bir drama çalışmasıdır. Ancak elimizdeki versiyonu Orta Çağ Çin edebiyatında Bianwen 'paralel düz yazı' benzeri bir tarza dönüştürülmüştür (Shimin 2002: 793).

Maitreya, Müslüman ve Hristiyan dünyasındaki 'Mehdi' kavramına paralel bir biçimde istikbalde gökten yere inip insanları nirvana'ya ulaştıracak olan bir Burkandır (Tekin 1976: 29). Burkan, ise Budizm'de beden isteklerini yenerek tanrısal bilgiye ulaşan ermiştir (Hançerlioğlu 1975: 112). Yani tam ve aşılamaz aydınlanmaya ulaşmış ve dünyevî acılardan tamamıla kurtulmuş insanı ifade eder. Budist edebiyatta, Skr. maitreya-vyākarana 'Maytrı hakkında kehanet' veya Skr. maitreya-samiti > Maytrisimit veya Maytrısımıt 'Maytrı ile buluşma' konularının birçok defa işlendiği görülmektedir. Bu konuyla ilgili Sanskritçe, Çince, Tibetçe Toharca, Soğdca ve Türkçe gibi çeşitli dillerde metinler bulunmaktadır (metinler için bk. Sertkaya 1982-1983: 253-255) .

'Maitreya ile Buluşma Temsili' demek olan maitreyasamitināțaka, Vaibhāṣika tarikatına bağlı, Agnidesa'da (Karaşehr/Karaşar) doğmuş Āryacandra tarafından Sanskritçeden Tohar diline göre telif-tercüme edilmiştir. Āryacandra'nın nāșaka temsilleri şeklinde olan bu eserini ülüş’ler 'bölüm' hâlinde İl Balık'lı (Koço'lu) Prajñärakșita Keș̣i Ācarya tercüme etmiştir (Özönder 1992: 11). Eserde Maitreya Burkan'ın menkıbevi hayatı anlatılır.

Eserin iki nüshası Sengim'de, üç nüshası Murtuk'ta, bir de nerede bulunduğu kaydedilmeyen bir nüshası olmak üzere altı nüshası bilinmekteydi. Sonradan Berlin'e götürülen bu nüshaların çoğu birbirini tamamlayan metinlerdir 


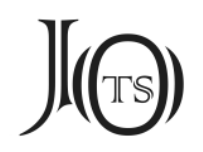

(Sertkaya 1986: 255). Bunların dışında 1959 yılında günümüz Çin Halk Cumhuriyeti'ne bağlı Uygur Özerk Bölgesindeki Hami (Komul) nahiyesinde Maytrisimit Nom Bitig'in 293 yapraklık bir nüshası daha bulunur (Sertkaya 1986: 253-280).

Maytrisimit adlı eserde anlatılanlar son derece canlı ve dramatiktir. Bu nedenle bazı araştırmacılar, bu eseri bir tiyatro metni olarak değerlendirmektedir. $\mathrm{Bu}$ öykülerin cemaat toplantılarında sadece okunmakla kalmayıp aynı zamanda sahneye konulduğu üzerinde de düşünülmektedir (Gabain 1988: 223). Bu sahnelenmeler Uygurlarda tiyatro sanatının başlangıcı sayılmakta, başka metinlerde körünçlük1 'sahne', körünççi 'seyirci', körünçlemek ${ }^{2}$ ‘seyretmek' sözcüklerinin de bulunması Uygurlarda tiyatro sanatının varlığını doğrulamaktadır (Tezcan 2003: 291). Yine bu konuda önemli fikirlere sahip olan araştırmacılardan biri de TEKíN'dir (1976: 31-32). O, hazırladığı çalışmasının giriş kısmında 'Maytrısimit'de Dramlaşma' başlı̆̆ıyla bu konu üzerinde durmuştur.

Bu görüşlere dayanarak makalede öncelikle eserdeki tiyatro eğilimleri tespit edilmeye çalışıldı. Bunun için eserin Berlin (B) koleksiyonu ve Hami (H) nüshasından tiyatro ile ilgili terimler, tiyatro teknikleri vb. kavramlardan örnekler seçilip eserin dil ve üslup bakımından bir sivil hayat belgesi olarak değerlendirilebileceği üzerinde duruldu. Makalede Berlin'deki nüshalar üzerinde çalışma yapan TEKIN'in (1976) ve Hami nüshası üzerinde çalışan SHIMIN'in (1980: 101-156) çalışmaları esas alındı.

TEKIN’in çalışmasında bir yükünç ‘secde’ ve 27 bölüm yer alırken SHIMiN’in çalışmasında Hami nüshasının sadece ikinci bölümü yer almaktadır.

\section{Eserdeki Tiyatro Terimleri ve Teknikleri}

Maytrisimit' in çeşitli yerlerinde metnin körünç 'temsil, piyes' sözcügü ile nitelendirilmesi bu eserin öyküden 'çatik' (< Skr. jätaka) çok bir tiyatro metnine

körünçlük 'üzerinde eşya sergilenen raf, pano, iskele' (EUTS: 79); 'an instrument for making appearances, a state chariot or the like' (EDPT: 746a ); 'vneshniy vid, primeta' (DS: 319).

körünçlemek 'teşhir etmek, sergilemek' (EUTS: 79); 'to display, make a show of (something) (EDPT: 746b); 'vistavlyaty' na popkaz' (DS 319); 'to display things' (OTWF: 440).

Bu kısımda, ilahî ve dünyevî varıkların, Burkan cemaati önünde saygı ile eğildikleri anlatılmaktadir. 
yaklaştığını gösterir. TEKİN'e (1976: 33) göre metnin bazı yerlerinden ve zeyillerindeki kayıtlardan Maytrisimit' in yeni yılda (yayı kün) ${ }^{4}$ veya ayın ilk gününde düzenlenen dinî bayramda bir piyes biçiminde temsil edildiği anlaşılmaktadır. Daha sonra da şunları ekler:

“Maytrı'nın halef olarak tayinini kutlayan mümin halk için düzenlenen dini eğlencelerde eser, yüksek sesle, türlü rahipler tarafından halka okunurdu. Uygur Burkan rahipleri de Hoçu gibi büyük şehir halklarına bazı geceler temsil verirlerdi. Bu piyeste musiki eşliğinde rahipler, eserde geçen türlü kişileri temsilen metni okurlar veya pandomima ile olayı temsil etmeye çalı̧ırlardı" (Tekin 1976: 35).

Ayrıca aynı konunun işlendiği Toharca metinde eser, Uygurca metinde olduğu gibi ülüşs 'bölüm' şeklinde değil, nātaka 'temsil' diye adlandırılmıştır. Bu yüzden Toharca metnin adı Maitreyasamiti-nāțaka olarak tespit edilmiştir (Sertkaya 1986: 255).

$\mathrm{Bu}$ açıklamalar eşliğinde metinde geçen körünç sözcügü son derece dikkat çekicidir. Metnin iki yerinde bu sözcük şu cümlelerde geçer:

alku tınlıg maytrlag yąı kün körünçinte menileyürler "Bu bütün yaratıklar Maytrı hakkındaki yeni gün piyesinde eğlenirler" (B 27/11).

maytrı burxan belgürer yajı kün küsençig körünç birle tuşar "Maytrı burkan görünecek ve o, yeni günde arzulanan piyese tesadüf edecektir" (B 104/9).

Ayrıca körünç sözcüğü ile aynı kökten gelen körk ${ }^{5}$ sözcüğü de 'resim, heykel' anlamlarında eserde kullanılmaktadır. Eserin her bölümünde olaya göre canlı

\footnotetext{
4 yaıı kün 'Bud. the firs day (of a period)' (EDPT: $943 b)$.

5 körmek 'görmek' (EUTS: 78), 'basically to see (something)', 'to look' (EDPT: 736a), 'videty', smotret"' (DS: 317), 'uvidet' (ESTY III: 77), 'see' (DLT III: 110); körünç 'piyes, görülecek olan şey.'(EUTS: 79), 'etymologically it should mean 'appearance' or the like; but in Xak. seems to have a more active meaning' (EDPT: 746a), 'videnie, zrelizhe' (DS: 319), 'appear to have signified an appearance, a display and perhabs a pageant' (OTWF: 282); körk 'güzellik, endam, alamet, nişan, biçim, kyyafet, heyet, resim' (EUTS: 78), 'basically something visible; shape, form and the like' (EDPT: 741a), 'obraz, jzobrazxenie; vid, priznak, primeta' (DS: 317), 'oblik, krasota; vid, naruzhnost' (ESTY III: 8182), 'beauty' [husn, jamāl] (DLT III: 110), 'appearance, shape, form, visual characteristic, beuty' (OTWF 224).
} 


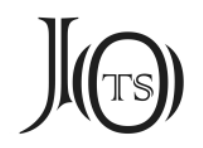

tasvirlerin yapıldığı dikkate alındığında belki de yukarıda bahsedilen dinî ritüellerde bu canlı ve renkli tasvirlere uygun olarak sahneye büyük boyda resimler, heykeller yerleştirilmekteydi.

Bu konuda Tibet'te yapılan bir uygulama hakkında bilgi veren KOEPPEN'in (1857: 310), açıklamaları ilgi çekicidir:

“Lhassa'da (Tibet) yeni yıl bayramı geçen yüzyılda şöyle kutlanırdı: Güreşler yapılır, piyesler oynanır bilhassa geceleyin manastırlar, halka dinî dramlar temsil ederlerdi: Canlı ve plastik resimler yalnız o gece için hazırlanır ve bunlar Burkan'ın hayatını temsile yarardı." (Tekin 1976'dan).

$\mathrm{Bu}$ açıklamayla birlikte tiyatro açısından körk sözcügünün eserdeki kullanımı daha da önem kazanmaktadır. Olayların geçtiği yeri ve olayın bir anını gösteren büyük boyda resimler dinleyicilerin karşısına konulmakta, olayın değişmesiyle yeni bir resim getirilmektedir (Tezcan 2001: 291). Böylece inananlar, Maytr1 ile buluşmayı ümit etmekte ve dinî vaazı dinleyerek ebedî kurtuluşa ulaşmayı dilemektedirler. Basit bir biçimde de olsa tiyatrodaki oyun konusunun geçtiği yeri, çevreyi ve atmosferi 'biçim, kalıp, renk, ışılama ve bazen de simgelerle canlandıran tamamlanmış sanatsal yapım' (Nutku 1983: 30) anlamına gelen dekor terimi ile karşılaşılmaktadır. Ayrıca bu, tiyatroda bir olayın sahnelenme tekniği ile de açılanabilir:

kruşlanmak körkle körküg 'güzel çehreyi' (B 96/13).

(kün) ay tyri körkin belgürtü(p) nomlayu yarlıkap (B 4/1-2) "güneş (veya) ay tanrısı kılığına girip".

burxan körkin itip (B 50/4) "burkan heykelleri yapıp”.

burxan (kör)kin suwka kigürser "burkan heykelini suya soksa" (B 51/3).

burxan körkin bodugin bezep agirlasar "burkan resimlerini renklerle süsleyip" (B 54/3).

burxan körkin ister yaratsar alku kutlug tinliglar maytrı burxan birle tegişürler yme kim kayu tınlıg süzük köglin çubakan ewin inçe vrhar ister arpa ewin inçe burxan körkin yaratsar "Burkan resimlerini süslese bütün mesut yaratıklar, Maytrı burkana rastlarlar. Yine hangi yaratık temiz kalple 'zyzyphus' tanesi kadar bir manastır inşa etse ve arpa tanesi kadar bir burkan heykeli yapsa" (B 104/23-28). 


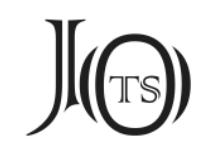

Yine bu temsillerin düzenlendiği eğlenceler sırasında temsilin bir parçası olan ve temsili tamamlayan oyun 'raks; musiki' ve oyunçı 'mızıkacı' gibi unsurlar da metinde yer almaktadır:

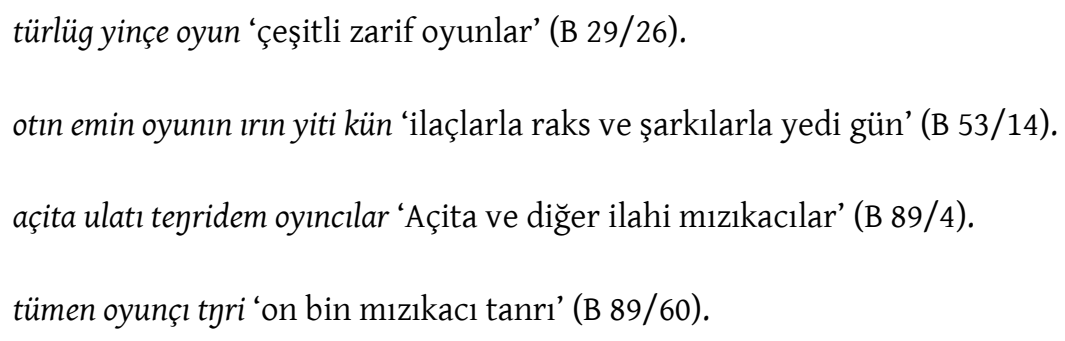

Eserin Berlin koleksiyonundaki nüshalar üzerinde çalışan TEKIN'in çalışması, bir yükü̈ç 's 'secde' ve 27 ülüş’ten 'bölüm’ oluşmaktadır. Hami nüshası üzerinde çalışan SHIMIN ise 25 bölümden sadece ikinci bölümü ele almıştır. Her iki nüshada da anlatılanlar, ülüş adı verilen bölümlerden oluşmaktadır. Eser bir temsil olarak düşünüldüğünde buradaki bölümler (ülüss) tiyatrodaki bir perdenin açılmasından kapanmasına kadar geçen ve ‘bölüm' anlamına gelen 'perdeler' olarak değerlendirilebilir (Nutku 1983: 110).

Eserde 'bölüm, perde' anlamlarında değerlendirebileceğimiz iki farklı sözcük kullanılmaktadır: ülüş ve bölük ${ }^{8}$. Metinde bu sözcüklerin geçtiği cümleler şunlardır:

\section{ülüş' 'bölüm, kısım; perde'}

baştınkı ülüş ‘birinci bölüm' (B 14/10).

törtünç ülüş ‘dördüncü bölüm' (B 27/28).

6 yükünç=Skr. namaskara (Edgerton 1953: 290b); 'secde, ihtiram, hürmet, sayg1, ululama' (EUTS: 199); 'an act of worship or obeisance' (EDPT: 913a); 'pokloneie, sovershenie, obrjado poklonenija, sovershenie molitvy' (DS 285); 'bow' [Arapça salāt; şa'şa'a ra's] (DLT III: 236); 'an act of worship' is clearly related to yükünmek' (OTWF: 279).

7 ülüş < üle-ş ‘share, portion' with some specific applications like 'chapter' (of a book) and 'fraction'; practically syn. up. and commoner than ülüg' (EDPT: 153a); 'çast', dolja, mera' (DS: 625); 'dolja, çast" (ESTY I: 28); ülüş ülüg [Arapça nasīb; tafrika al-ansibā’] (DLT III: 59).

8 bölük <böl-ük 'section, part' (EDPT: 339b); 'glava, otdel, pazdel' (DS: 118); 'otdelenie, otdel, otrjad, glava' (ESTY II: 216); [Arapça şā'ifa; kaşí'] (DLT III: 79); 'to get into separate flocks and assemble in them is a hap.' (OTWF: 646). 


\section{J(৫)}

bir otuzunç ülüş ‘yirmi birinci bölüm' (B 64).

iki otuzunç ülüş̧ ‘yirmi ikinci bölüm’ (B 68).

biş otuzunç ülüş ‘yirmi beşinci bölüm' (B 81, 82, 83).

ikinti ülüş ‘ikinci bölüm’ (H 1a).

\section{bölük 'bölüm; perde'}

bir ygirminç bölük nom tükedi ‘on birinci bölüm bitti’ (B 38/57).

Ayrıca eserde ülüş diye adlandırılan bölümlerin içinde ve bu bölümlerden daha küçük bölümler yer almaktadır. Bunlara ise eserde ptr (< Skr. pattra 'kitap sahifesi') adıverilmektedir. Bu da tiyatrodaki bir perdenin dekor değişikliğiyle belirlenen alt bölümlerinden oluşan 'tabloları' akla getirmektedir (Nutku 1983: 132).

Bir perde çeşitli tablolara bölünmüş olabilir:

altınç tokuz ptr 'altıncı bölüm dokuzuncu yaprak' (B 32).

bir ygirmi ptr 'on birinci yaprak' (B 85).

bişinç iki ygirmi ptr 'beşinci bölüm on ikinci yaprak' (B 31).

onunç iki ptr ‘onuncu bölüm ikinci yaprak' (B 33).

ikinti ülüş iki ptr 'ikinci bölüm ikinci yaprak' (H 2a).

ikinti ülüş tört ptr 'ikinci bölüm dördüncü yaprak' (H 4a).

Tiyatro metinlerinde kişilerin konuşmaları sırasında yapacakları jest ve mimikler parantez içinde verilir. Jest, oyunculukta iç yaşamı belirginleştiren baş, el, kol hareketleri (Nutku 1983: 75), mimik ise düşünceleri, duyguları yüz ve gövde anlatımı ile verme sanatıdır (Nutku 1983: 91). Maytrisimit'te de bu tekniğe benzer bir ifade dikkat çekmektedir. Bununla ilgili her bölümde çokça örnek yer almaktadır. Bazı bölümlerden bu teknik ile ilgili şu örnekler verilebilir:

amal tünün (...) tükel bilge ma(ytri) (...)kşanın yarataghg (...) önüp ayasın kawşu(rup) (inçe) (tip) ötünür "sakin bir gecede (...) mükemmel Maytrı (...) alametler ile mücehhez (...) çıkıp ellerini kavuşturup hürmetle (şöyle der)” (B 26/8-12). 


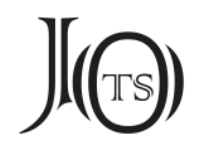

badari braman ulug karı bükülmiş etözin kirt kirt külçire inçe tip "Badhari Brahman bükülmüş vücudu ile kıkır kıkır gülerek şöyle dedi” (B 12/18-19).

anı işitip badari braman küler yüzin kutgurur kaşın tegridem urungu tapa körü mujadu adınu inçe tip tidi "Bunu işitince Badhari brahman güler yüzle saadetler bahşeden kaşları ile ilahi kumandana doğru baktı ve hayret ve şaşkınlıkla şöyle dedi” (B 13/4-6).

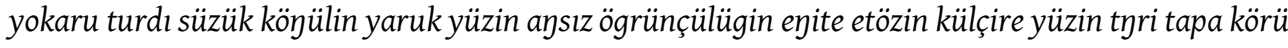
inçe tip tidi “Temiz bir gönülle, parlak bir yüzle, fevkalade bir sevinçle, iki büklüm vücudu ile güler yüzle tanrıya doğru bakarak şöyle dedi” (B 13/26-29).

bu saw(ag) (sözleyür) erken elgin yokaru (öntürüp) agırlayu "Bu sözleri söylediği sırada Brahman Nirdhana ellerini yukarı kaldırıp hürmet ile” (B 10/19-20).

aniy ara urlar kuwragin tegriklep akru akru majlayu ayagka tegimlik maitri badari bramanka yakin tegip (ili)gin yokaru kötürüp öküş türlüg ayayu agırlayu inçe tip tidi “O sırada hürmetli Maytrı oğlanlar cemaatinin çevresini kuşatıp yavaş yavaş adım atıp Badhari brahmana yaklaşarak, ellerini yukarı kaldırıp çokça hürmet edip şöyle dediler" (H 1a/6-11).

ötrü külçire yüzin tüzün maitri inçe tip tidi "Ondan sonra, müşfik Maytrı, gülümseyip şöyle dedi” (H 1a/29-30).

ötrü titreyü etözin badari braman inçe tip tidi “Ondan sonra, Badhari braman vücudu titreyerek şöyle dedi” (H 2b/19-20).

Metnin her bölümünün başlarında olayların geçtiği yerlere dair bilgiler yer almaktadır. Bu da tiyatro sahnesinde olaylara uygun 'dekor' kavramını hatırlatmaktadır. Buna bağlı olarak bu bölümlerde seyircinin/dinleyicinin 'tasavvur etmesi' (ukmış krgek) istenerek canlı ve renkli tasvirlerin oluşması sağlanır. Bu sözün kullanılması da eserin bir temsil değeri taşıması açısından dikkat çekicidir. Bu bölümlerden bazıları şunlardır:

amtı bu nomlug sawag ą magt ilte racagri kent uluşda ukmış krgek (...) anta ötrü vayşarvan magaracnì üç ulug küçlüg inanç buyrukları erti (...) sadagari hymavati purnaki bular üçegü kök kalıdakı yolça uça kelip bir ikintişke sawin sözleşü purnaki inçe tip tidi körü̈ler küçlügler (...) bu yirtinçüde ansız öküş nomlug telim taşım çog yalın belgülüg bolmış erür anta ötrü hymavati inçe tip tidi (...) amtıkıya yakuru yirde ödde belgülüg bolmış erür (...) "Şimdi bu dinî hadiseyi, fevkalade Magadha ülkesinde, Rajagrha adlı baş şehirde tasavvur etmek lazımdır. Vaişravana adlı büyük hükümdarın pek çok güçlü üç nedimi ve vekili Sadagiri, Haimavati ve Purnaka idi. Bu üçü gökteki yol boyunca uçarak geldiler. Birbirleri ile sohbet ederlerken Purnaka şöyle dedi: Bakın, kudretliler! Bu dünyada fevkalade, büyük dinin gür ışı̆̆ı belirmiştir. Bunun üzerine Haimavati şöyle dedi: İşte şimdi yakın yer ve zamanda belirmiş (...)” (B 7/2-17). 


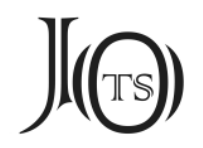

amtı bu nomlug sawag badari bramnıy e(w)inte ukmış krgek anta ötrü badari braman tay yarunınta turup silik (inçe) tip tidi "Şimdi bu dinî hadiseyi Badhari brahmanın evinde tasavvur etmek lazımdır. Bunun üzerine Badhari brahman, kalktı şöyle dedi” (B 15/2-6).

sögüt tüpinte (vaj) rrlıg örgün üze o(luru)p burkan kutın bulgay siz anta ötrü ayagka tegimlig bodisvt tebrençsiz etözin tütrüm teriy dyan sakınç yügerü kılur "Ağacı dibinde elmas taht üzerine oturup burkanlığa ulaşacaksınız. Bunun üzerine hürmete layık bodhisattva sarsılmaz vücudu ile derin istiğraka şimdi dalar" (B 39/1-6).

amtı bu nomlug sawag kitumati balkkta ukmış krgek anta ötrü çaladr yulta erdeçi calaprbasi atliglular kanı tükel bilge maytrı burxannı lu ordusina yagumışın ukup (...) "Şimdi bu dinî hadiseyi Ketumati adlı şehirde tasavvur etmek lazımdır. Bunun üzerine Jaladhara adlı bir gölde yaşayan Jalaprabhasa adlı ejderler hükümdarı mükemmel hikmetli Maytrı burkanın ejderler sarayına yaşlaştı̆̆ını anlayıp (...)" (B 53/2-8).

amtı bu nomlug sawag kitumati atlig uluştakı samntapuş seyremte ukmış krgek "Şimdi bu dinî hadiseyi Ketumati adlı şehirdeki Samantapuşpa manastırında tasavvur etmek lazımdır" (B 55/ 7-9).

amtı bu nomlug sawag smantavrkaş yazıda ukmış krgek (...) anta ötrü kök kalıkda tüklüg tümnelig örtlüg yalınlı $k($ ar)a bult osuglug tütünl(üg) (...) ikenmiş ulug etözlüg ul(ıyu) (sı)ktayu korkıncıg öglüg menizlig tamuluglar kelirler "Şimdi bu dinî hadiseyi Samantarksa adlı ovada tasavvur etmek lazımdır. Bunun üzerine gökte on binlerce kızgın alevli kara bulutlar gibi duman (...) büyük vücutlular ağlayıp inleyerek korkunç renkli yüzleri ile cehennemlikler gelirler" (B 68/1-9).

amtı bu nomlug sawag $k(. .$.$) kukutapat tagka sma(ntavrkaş) atlig ya(zı)da (ukmış) (krgek) ant(a)$ (ötrü) adan yük (...) ödteki otın yalının (yörgen)miş ulug bedük bullt (osu)glug sansiz tümen kolti nayut san(1)nca kicig tamuluglar kelirler "Şimdi bu dinî olayı Kukkutapada dağında, Samantavrksa adlı ovada tasavvur etmek gerekti. Bunun üzerine başka devirde ateş ve alevlerle çevrilmiş büyük muazzam bir bulut gibi sayısız ufak cehennemlikler gelirler" (B 70/2-9).

Hami nüshasıyla ilgili çalışmada sadece ikinci bölüme yer verildiği için bu hususla ilgili bir örnek tespit edilmiştir:

amtı bu nomlug sawag badari bramannı ewinte ukmış krgek (...) "Şimdi, bu dinî hikâyeyi Badhari brahmananın evinde tasavvur etmek gerekir" (H 1a/2-3).

Eserde tiyatroda görülen karşllıklı konuşmalar yani diyaloglar bulunmaktadır. Bu karşılıklı konuşmaların yer aldığ cümlelerde inçe tip tidi 'şöyle dedi' sözü kullanılmakta ve diyaloglar bu sözle kurulmaktadır. 
amtı bu nomlug sawag ay magt ilte racagri kent uluşda ukmış krgek (...) anta ötrü vayşarvan magaracniø üç ulug küçlüg inanç buyrukları erti (...) sadagari hymavati purnaki bular üçegü kök kalıdakı yolça uça kelip bir ikintişke sawin sözleşü purnaki inçe tip tidi körü̈ler küçlügler (...) bu yirtinçüde ansız öküş nomlug telim taşım çog yalın belgülüg bolmış erür anta ötrü hymavati inçe tip tidi (...) amtıkıya yakuru yirde ödde belgülüg bolmış erür "Şimdi bu dinî hadiseyi, fevkalade Magadha ülkesinde, Rajagrha adlı baş şehirde tasavvur etmek lazımdır. Vaişravana adlı büyük hükümdarın pek çok güçlü üç nedimi ve vekili Sadagiri, Haimavati ve Purnaka idi. Bu üçü gökteki yol boyunca uçarak geldiler. Birbirleri ile sohbet ederlerken Purnaka şöyle dedi: Bakın, kudretliler! Bu dünyada fevkalade, büyük dinin gür ışı̆̆ı belirmiştir. Bunun üzerine Haimavati şöyle dedi: İşte şimdi yakın yer ve zamanda belirmiş" (B 7/2-17).

anta ötrü badari braman tay yaruninta turup silik inçe tip tidi (...)munta kim sizler anı̇ (...)-lar kuvragin (...) akru aku (...) belgürmiş erür "Bunun üzerine Badhari brahman şafak sökerken kalktı (...) şöyle dedi: Burada kim sizler onun (...) cemaat ile (...) yavaş yavaş zuhur etmiştir" (B 15/4-10).

ötrü külçire yüzin tözün maytrı inçe tip tidi antag erser (ayagka) tegimlig (...) törüde etözümin (...) (n)ey asagin bulmadım (...) ajunlug taluy ögüztin (...) an kininte (...)irinç yarlgda yarlıg mn karı kul boltum kim munta (kutgar)dacı kutlug tınlıgag körmedin alku adada kutgarguçı adınçıg tgri tgrisi burxan körmedin ölür mn anta öt(rü) ol tyri badari (braman)ka inçe (tip) tidi emgek(lig) (b)usuşlug bolmang burxan (belgürmek) trak ol tip tigülüg törü (bultu)kmaz ne üçün tip tiser köjül (...) ödte asangı saninça (...) uluş balıklarka tegip sansız (...) tınliglarka asag tusu (kilmış) (er)yek sukıginça ödte "Sonra gülümseyen yüzü ile asil Maytrı şöyle dedi: “ Böyle ise hürmete layı (...) düzende vücudumu (...) hiç faydasını görmedim. (...) dünya denizinden (...) en sonunda (...) sefilin sefiliyim ben. İhtiyar bir kul oldum. Bütün dertlerden kurtaran mukaddes yaratı̆̆ görmeden bütün tehlikelerden kurtaran harikulade Tanrılar Tanrısı Burkanı görmeden öleceğim!" Bunun üzerine Tanrılar Tanrısı Badhari Brahmana şöyle dedi: Dertlenip tasalanmayın! Bir Burkan zuhuru uzaktır diye söylenen rivayet doğru değildir. Neden gönül şehirlere varıp sayısız (...) yaratıklara hizmet ettiği bir parmak teması kadar bir zamanda" (B 15/14-18, 16/1-18).

tyri tyrisi burxan gautami katun ogrnnta yiti türlüg sangalamban atlig buyan bökteg kllmakniy utllsin tüşin kingürü yarlkkadl (...) ol ödte berü alku cambudvip uluştakı tınlılar (...) öküş türlüg buyan edgü kılınç (kı)lurlar (...) bu sawag eşidip bayagut kuncuy inçe tip tidi (...) tirtiler (...) bay er inçe tip tidi (...) kamag ödün kalın kuwrag aşın içgün tapıngu udungu küçüm küsünüm teginmez (...) anın amtı kamag bursay kuwragdın iki toyın ötünü teginür mn kim küntemek menin ewimte aşanzunlar (...) mn yme küçüm (yit)mişçe tapınıp ajunlug azuk (...) "Tanrılar Tanrısı Burkan, kraliçe Gautami'nin hatırı için yedi çeşit Samghalambana adlı iyi amel işlemenin faydasını tafsilatı ile buyurdu. Bu sözleri işitince zengin bir kadın şöyle dedi: (...) Yanlış itikat hocaları (...) Zengin bir adam şöyle dedi: Her zaman büyük bir cemaate yiyecek ve içecek ile hizmet etme gücüm kudretim yoktur. Bu yüzden şimdi her cemaatten iki rahip istiyorum, her gün benim evimde yesinler, ben de gücüm yettiğince hizmet edip dünyevî azık (...)" (B 25/ 1-20). 


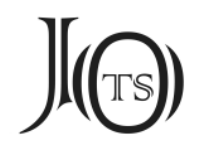

badari bramanka inçe tip tidi (...) körüy bilge bagsı bu tükel bilge tyri tyrisi burxan ç(a)krirt ilig xantın k(e)lmiş (...) ötrü titreyü etözin badari braman inçe tip tidi (...) amrakoglum senin bu muntag türlüg sözleyü yitinçsiz kut buyan edgügin erdeminin körüp ertipü muyadur mn adınur mn "(Maytrı) Badhari bramana şöyle dedi: "Bakın, bilge üstat, bu mükemmel bilge tanrılar tanrısı Burkan-cakravarti handan gelmiş (...) Sonra Badhari braman titreyerek şöyle cevap verdi: Sevgili oğlum, senin bu şekilde konuşarak, ulaşılmayan sevabın faziletini görünce fevkalade şaşırdım" (H 2b/15-24).

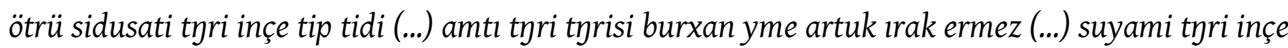
tip tidi (...) anı yme titirü körünler "Ondan sonra, Sidusati Tanrı şöyle dedi: "Şimdi tanrılar tanrısı Burkan da artık uzak değildir. (O sırada) Suyami Tanrı, şöyle dedi: "Onu da dikkatle görün" (H 9b/17-22).

Yine eserde, bazı bölümlerde yer alan kişilerin isimleri zikredilmektedir. S1rası gelince sahnede görünen ya da konuşan çeşitli kişiler/oyuncular ile karşılaşılmaktadır.

\begin{abstract}
küçlüg tyriler birle timburi pançasiki şitrasiki nata açita ulatı tengridem oyınçlar birle vişvakrami tyride ulatı tyridem uz uzagutlar birle trtraştri virutaki, virupaksa, vaişravana "kuvvetli tanrılar ile Timburi, Pançasiki, Şitrasini, Nata, Açita ve diğer ilahî mızıkacılar ile Vişvakrami tanrıdan başka semavî ustalar ile Trayastrimsah Virutaki, Virupaksa, Vaişravana" (B 89/2-9).

amtı bu nomlug sawag ay magt ilte raçagri kent uluşda ukmış krgek (...) anta ötrü vayşarvan magaracning üç ulug küçlüg inanç buyrukları erti (...) sadagari hymavati purnaki bular üçegü kök kalıdakı yolça uça kelip bir ikintişke sawin sözleşü purnaki inçe tip tidi körü̈ler küçlügler (...) bu yirtinçüde aysız öküş nomlug telim taşım çog yalın belgülüg bolmış erür anta ötrü hymavati inçe tip tidi (...) amtıkıya yakuru yirde ödde belgülüg bolmış erür (...) "Şimdi bu dinî hadiseyi, fevkalade Magadha ülkesinde, Rajagrha adlı baş şehirde tasavvur etmek lazımdır. Vaişravana adlı büyük hükümdarın pek çok güçlü üç nedimi ve vekili Sadagiri, Haimavati ve Purnaka idi. Bu üçü gökteki yol boyunca uçarak geldiler. Birbirleri ile sohbet ederlerken Purnaka şöyle dedi: Bakın, kudretliler! Bu dünyada fevkalade, büyük dinin gür sşı̆̆ı belirmiştir. Bunun üzerine Haimavati şöyle dedi: İște şimdi yakın yer ve zamanda belirmiş" (B 7/2-17).
\end{abstract}

Bu cümlelerde görüldüğü üzere gerek tanrılar arasındaki konuşmalarda gerek ilahî mızıkacılar ile semavî ustalar ve gerekse hükümdarlarla nedimleri arasındaki diyaloglarda dikkat çeken canlılık, dramatik ögeler ve anlatım tekniği bu metnin âdeta bir tiyatro eseri biçiminde gözümüzde canlanmasına sebep olmaktadır. Ayrıca bu diyalogların arasına Buda ve Budist düşüncede kendini tüm duyarlı canlıların Budalığa ulaşmasına yardımcı olmaya adamış bodhisatva'ların (Hancerlioğlu 1975: 107) başından geçen olaylar yerleştirilmiştir. Böylece rahip 


\section{$J(\Theta)$}

olmamakla birlikte Budizm'i kabul eden halk topluluklarına dinsel coşku verilmeye çalışılmıştır.

\section{Sonuç}

Uygur dönemi edebiyatı farklı dinlere ait çevrelerde çeşitli eserlerin yazıldığı/çevrildiği ve yoğun edebî faaliyetlerin gerçekleştirildiği bir dönemdir. Sadece edebî metinlerin değil aynı zamanda pek çok sivil hayat belgesinin de bulunduğu bu dönemde biyografi, tövbe duaları, büyü ve sağlık metinleri, hukuk belgeleri, mektuplar, gökbilim, takvim ve yıldız falı üzerine yazılmış pek çok sivil hayat belgesi diye adlandırabileceğimiz metinler de yer almaktadır. Bu sivil hayat belgeleri için bk. Tezcan 2001: 271-324. Maytrisimit ise yazılış amacı ve içeriği açısından bu metinlerden ayrılırken dil ve anlatım bakımından bu metinlere yaklaşmaktadır.

Maytrisimit adlı eserin bir sivil hayat belgesi olarak değerlendirmesi üzerine yapılan bu çalışmada, eserden hareketle bazı tiyatro terimlerinin ve tiyatro tekniklerinin olabileceği görüldü. Yer yer eserde geçen ülüş ve körünç gibi terimlerin kullanılmasının yanı sıra tiyatroda karşılaşılan karşılıklı konuşmaların (diyaloglar) bulunması; basit de olsa sahne, dekor ve oyuncu kavramlarının varlığı eserin dramatik özellikleri olarak dikkat çekmektedir. Maytrisimit'in tiyatro eserine benzediği ya da sahnelendiği gibi görüşler, eserin okunduğu/temsil edildiği dinî törenlerle birlikte ele alındığında daha da güçlenmektedir.

Tiyatro ile ilgili bu terim ve tekniklerin Maytrisimit gibi dinî içerikli bir eserde yer alması, bu eserin sivil hayat belgesi olarak değerlendirilebileceğini düşündürmektedir. Metnin daha çok tiyatronun dil ve tekniğiyle kurgulanmış olması, eserin temsil gücünü artırdığı kadar aynı zamanda halka Budizm öğretilerini daha anlaşılır bir şekilde aktarmaya yönelik bir çabanın sonucudur. Bilinçli bir tercih olarak kendisini gösteren bu çaba, Budist çevreye ait sudur (<Skr. sūtra) ve abidarmalar'da (< Skr. abhidharma) görülmemektedir. Bu nedenle dönemin diğer dinî metinlerinde dil, daha fazla yabancı sözcük ve terimlerden oluşurken Maytrisimit'te Türkçe sözcük sayısının daha yoğun olduğu dikkat çekmektedir. 


\section{J(৫)}

\section{Kisaltmalar}

DLT = Dankoff-Kelly 1982, 1984, 1985.

DS = Nadelyayev et alii 1969 .

EDPT = Clauson 1972 .

ESTY = Sevortyan 1974-1978-1980.

EUTS = Caferoğlu 1968

OTWF = Erdal 1991.

Skr. = Sanskritçe

\section{Kaynakça}

BARUTÇU, F. S. (1992). "Eski Türkçede Buddha'nın 32 Lakșaṇası", Türk Dili Araştırmaları Y1llığ1 Belleten 1987: 11-33.

CAFEROĞLU, A. (1968). Eski Uygur Türkçesi Sözlüğü, İstanbul: Edebiyat Fakültesi Matbaası.

CLAUSON, S. G. (1972). An Etymological Dictionary of Pre-Thirteenth Century Turkish. Oxford: Oxford University Press.

ÇANDARLIOĞLU, G. (2002). “Uygur Devletleri Tarihi ve Kültürü”, Türkler, C. 2, Yeni Türkiye Yayınları, Ankara: 9-45.

ÇANDARLIOĞLU, G. (2004). Sarı Uygurlar ve Kansu Bölgesi Kabileleri (9.-11. Asırlar), İstanbul: Türk Dünyası Araştırmaları Vakfı.

DANKOFF, R.; J. KELLY (1982). Mahmut el-Kāşrarī: Compendium of the Turkic Dialects (Dīvān Luүāt at-Türk), Part I, Harvard: Harvard University Press.

DANKOFF, R.; J. KELLY (1984). Mahmut el-Kāşrarī: Compendium of the Turkic Dialects (Dīvān Luүāt at-Türk), Part II, Harvard: Harvard University Press.

DANKOFF, R.; J. KELLY (1985). Mahmut el-Kāşrarī: Compendium of the Turkic Dialects (Dīvān Luyāt at-Türk), Part III, Harvard: Harvard University Press.

EDGERTON, F. (1953). Buddhist Hybrid Sanskrit, Grammar and Dictionary, Vol. II, London: Oxford University Press. 


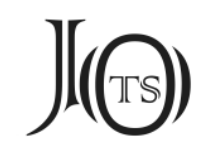

ERDAL, M. (1991). Old Turkic Word Formation, a Functional Approach to the Lexicon, Vol. I-II, Wiesbaden: Harrassowitz Verlag.

GABAIN, A. von (1988). Eski Türkçenin Grameri. Çev. M. AKALIN. Ankara: Türk Dil Kurumu Yayınları.

HANÇERLIOĞLU, O. (1975). İnanç Sözlüğü, İstanbul: Remzi Kitabevi.

İZGİ, Ö. (1987). Uygurların Siyasî ve Kültürel Tarihi, Ankara: Türk Kültürünü Araştırma Enstitüsü.

KAFESOĞLU, İ. (1976). “Uygurlar”, Türk Dünyası El Kitabı, Türk Kültürünü Araştırma Enstitüsü Yayınları, Ankara: 145-150.

KOEPPEN, C. F. (1857). Die Religion des Buddha und ihre Entstehung, Berlin: Ferdinand Schneider.

KORKMAZ, E. (2003). Eski Türk İnançları ve Şamanizm Terimleri Sözlüğü, İstanbul: Anahtar Yayınları.

MONIER-WILLIAMS, S. M. (1899). A Sanskrit-English Dictionary, Etymologically and Philologically Arranged with Special Reference to Cognate Indo-European Languages, Oxford.

NADELYAYEV, V. M. et alii (1969). Drevnetyurkskiy Slovar', Leningrad: Akademiya Nauk SSSR.

NUTKU, Ö. (1983). Gösterim Sanatları Terimleri Sözlüğü, Ankara: Türk Dil Kurumu Yayınları.

ÖGEL, B. (1948). “ilk Töles Boyları”, Belleten, 12: 795-833.

ÖZÖNDER, S. B. (2002). “Eski Türklerde Dil ve Edebiyat”, Türkler, C. 3, Yeni Türkiye Yayınları, Ankara: 481-501.

SERTKAYA, O. F. (1986). “Maitrisimit Nom Bitig”, Türk Dili Araştırmaları Yıllı̆̆ı Belleten 1982-1983: 253-280.

SEVORTYAN, E. V. (1974-1978-1980). Etimologiçeskiy Slovar Tyurkskih Yazıkov, III-III, Moskva: Nauka.

SHIMIN, G. (1980). "Kedimki Uygurçe İptidayi Drama Piyesasi “Maitrisimit” (Hami Nüshasi)ning 2-Perdesi Hekkidiki Tetkikat”, Türklük Bilgisi Araştırmaları, 4: 101-156. 


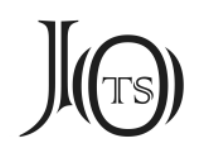

SHIMIN, G. (2002). "Budist Uygur Edebiyatı", Çev. B. BEKTAŞ; M. DELIKARA, Türkler, C. 3, Yeni Türkiye Yayınları, Ankara: 786-798.

TAŞAĞIL, A. (2002). “Uygurlar”, Türkler, C. 2, Yeni Türkiye Yayınları, Ankara: 215224.

TEKIN, Ş. (1962). “Mani Dininin Uygurlar Tarafindan Devlet Dini Olarak Kabul Edilişinin 1200. Yıldönümü Dolayısı İle Birkaç Not”, Türk Dili Araştırmaları Yıllı̆̆ı Belleten 1962: 1-11.

TEKIN, Ş. (1976). Uygurca Metinler II: Maytrısimit. Burkancıların Mehdisi Maitreya ile Buluşma, Uygurca İptidaî Bir Dram (Burkancılı̆̆ın Vaibhāṣika Tarikatına Ait Bir Eserin Uygurcası). Ankara: TDK Yayınları

TEZCAN, S. (2001). “En Eski Türk Dili ve Yazını”, Bilim Kültür ve Öğretim Dili Olarak Türkçe, 3. Baskı, Ankara: Türk Tarih Kurumu Yayınları. 